\title{
Analysis and Research on Risk Assessment of Financial Supply in Internet Supply Chain
}

\author{
Li Yifei \\ College of Social Science, Michigan State University, 48823, USA
}

Keywords: Internet finance, Internet supply chain finance, Risk assessment

\begin{abstract}
Internet supply chain finance has emerged along with the development of the Internet and the popularity of e-commerce. Internet supply chain finance can be classified in different ways, but regardless of which model, its main risks can be classified into credit risk, operational risk, environmental risk and security risk. In this paper, the fuzzy comprehensive evaluation method is used as the research method to evaluate the operational risk of Internet supply chain finance, and the corresponding prevention thinking is put forward.
\end{abstract}

\section{Internet supply chain finance}

\subsection{Internet finance}

In theory, all Internet applications involving generalized finance can be defined as Internet finance, including but not limited to models such as online payment, e-banking, virtual currency, and crowdfunding. However, from a financial point of view, internet finance should be defined at the level of currency credit, that is, funds are integrated through information technology through information technology. In China, Xie Ping and Zou Chuanwei put forward the concept of Internet financial model for the first time. They believe that the Internet financial model has subverted our own traditional financial model and created an indirect financing model that is neither a commercial bank in the past. It is also not the third financing model of the direct financing model of the previous capital market.

\subsection{Internet finance chain}

Internet supply chain finance is a new financing model that combines the characteristics of supply chain finance and internet finance. It refers to a commercial bank or a core enterprise or e-commerce that has the identity of the supply chain controller, the fund provider, and the e-commerce platform operator. On the basis of analyzing the large amount of credit data accumulated in the long-term supply chain transactions and the integrity system. It introduced the means of supervision of fund payment instruments by means of self-compensated trade financing and credit, and engaged in the e-commerce platform. The SMEs in the transaction provide a new financial model for closed credit support and other financial services such as fund management and payment settlement. The theoretical basis of Internet supply chain finance is information asymmetry theory, self-compensating trade financing theory and principal-agent theory. It makes up for the shortcomings of supply chain finance and internet finance, and has the potential to solve the problem of "financing difficulties and financing" for SMEs, which is of great benefit to the development of SMEs and even the real economy in China.

\subsection{The development of the Internet financial chain}

Internet supply chain finance was first piloted by Ping An Bank in China in 1999. In 2003, it proposed the concept of "self-compensated trade financing" and launched the " $1+\mathrm{N}$ " supply chain financing model. Everbright Bank puts forward the concept of "logistics banking” and uses it in supply chain financing. China Construction Bank first advocated the integration of supply chain and intermediary business to improve the financing efficiency of SMEs. In 2009, China Europe International Business School cooperated to complete related books and laid the theoretical 
foundation. With the recognition of "supply chain finance" by the International Financial Capital Summit, the four major state-owned banks and small and medium-sized banks have successively launched supply chain financial services in the true sense. At this stage, the supply chain finance and business operation system was officially established.

\section{Internet supply chain financial model}

Internet supply chain finance is mainly divided into three main modes: bank-oriented online supply chain finance, Internet supply chain finance led by e-commerce companies, and Internet finance jointly conducted by banks and e-commerce companies.

The above three models mainly carry out three kinds of Internet supply chain financial services such as B2B, B2C and C2C. Specifically, B2B is an Internet finance institution that conducts order financing and warehouse receipt financing for corporate customers. B2C is an online financial institution that conducts order financing or receivables financing for individual customers. C2C is an Internet financial institution that only plays The role of the intermediary platform is the individual's investment or financing of individuals.

\section{Internet supply chain risk}

Internet supply chain financial risks can be classified into credit risk, operational risk, security risk and environmental risk according to risk factors. credit risk. Based on the e-commerce platform, the Internet supply chain finance can rely on customer transactions and payment data analysis and mining to fully grasp the situation, and can accurately judge its credit status, which is conducive to credit risk prevention. On the other hand, customers only need to provide identity information through the network, and the credit risk is easily converted into operational risk. Operational risk. Internet supply chain finance has high requirements for practitioners. It requires a combination of Internet and financial knowledge to carry out business. At present, there is a shortage of talents in this area, which will face greater operational risks. Security Risk. Internet supply chain finance needs to be more rigorous in the design and application process of financial platforms. Once there is a problem with the platform hardware or software, it will lead to security risks. Environmental risks. Internet supply chain finance has greatly expanded the types of pledges or collateral, increasing the number and size of lenders and investors.

\section{Financial Risk Assessment of Internet Supply Chain Based on Fuzzy Comprehensive Evaluation Method}

The evaluation mode is determined according to the operational flow of the above table. First, the analytic hierarchy process is used to determine the weight of each indicator, and the scale method is used to compare the structural judgment matrix. As shown in the table below.

\begin{tabular}{|c|c|c|c|c|c|}
\hline & $\begin{array}{c}\text { Process design } \\
\text { operation risk } \\
\text { W1 }\end{array}$ & $\begin{array}{c}\text { Technical } \\
\text { operation risk } \\
\text { W2 }\end{array}$ & $\begin{array}{c}\text { Personnel operation } \\
\text { risk W3 }\end{array}$ & $\begin{array}{c}\text { Regulatory } \\
\text { operational risk } \\
\text { W4 }\end{array}$ & $\begin{array}{c}\text { Cooperative risk } \\
\text { W5 }\end{array}$ \\
\hline $\begin{array}{c}\text { Process design } \\
\text { operation risk W1 }\end{array}$ & 1 & 3.263 & 4.985 & 2.921 & 2.985 \\
\hline $\begin{array}{c}\text { Technical } \\
\text { operation risk W2 }\end{array}$ & 0.306 & 1 & 4.365 & 2.853 & 2.152 \\
\hline $\begin{array}{c}\text { Personnel } \\
\text { operation risk W3 }\end{array}$ & 0.201 & 0.229 & 1 & 0.836 & 0.425 \\
\hline $\begin{array}{c}\text { Regulatory } \\
\text { operational risk } \\
\text { W4 }\end{array}$ & 0.342 & 0.351 & 1.196 & 1 & 0.896 \\
\hline $\begin{array}{c}\text { Cooperative risk } \\
\text { W5 }\end{array}$ & 0.335 & 0.464 & 2.353 & 1.116 & 1 \\
\hline
\end{tabular}


Normalize each column of matrix A :

\begin{tabular}{c|l|l|l|l|l}
\hline & 0.458 & 0.615 & 0.359 & 0.335 & 0.400 \\
\hline & 0.140 & 0.188 & 0.314 & 0.327 & 0.289 \\
\hline Aij= & 0.092 & 0.043 & 0.072 & 0.096 & 0.057 \\
\hline & 0.157 & 0.066 & 0.086 & 0.115 & 0.120 \\
\hline & 0.153 & 0.087 & 0.169 & 0.128 & 0.134 \\
\hline
\end{tabular}

Add each column and further normalize it:

\begin{tabular}{c|l|l}
\hline & 0.433 & \\
\hline & 0.252 & \\
\hline $\mathrm{Wi}=$ & 0.072 & \\
\hline & 0.109 & \\
\hline & 0.134 & \\
\hline
\end{tabular}

Consistency test was performed: $\mathrm{CRk}=0.035 \leq 0.1$, so the comparison matrix was found to have satisfactory consistency.

In the following, the fuzzy comprehensive evaluation method is introduced to construct the financial operation risk evaluation model of the Internet supply chain to evaluate its operational risk. First, the risk equivalence is divided into: R1, the risk is very low; R2, the risk is relatively small; $\mathrm{R} 3$, the risk is moderate; R4, the risk is greater; R5, the risk is extremely high. The corresponding set of scores is $R=\{50,40,30,20,10\}$. Secondly, the survey yielded a fuzzy evaluation relationship matrix V:

\begin{tabular}{|c|c|c|c|c|}
\hline 0.4 & 0.3 & 0.2 & 0.1 & 0 \\
\hline 0.2 & 0.3 & 0.3 & 0.1 & 0.1 \\
\hline 0.5 & 0.3 & 0.1 & 0.1 & 0 \\
\hline 0.3 & 0.4 & 0.2 & 0.1 & 0 \\
\hline 0.2 & 0.4 & 0.1 & 0.2 & 0.1 \\
\hline 0.4 & 0.3 & 0.1 & 0.2 & 0 \\
\hline 0.3 & 0.4 & 0.3 & 0 & 0 \\
\hline 0.2 & 0.5 & 0.2 & 0.1 & 0 \\
\hline 0.4 & 0.3 & 0.3 & 0 & 0 \\
\hline 0.3 & 0.2 & 0.2 & 0.2 & 0.1 \\
\hline 0.3 & 0.3 & 0.3 & 0.1 & 0 \\
\hline 0.2 & 0.2 & 0.4 & 0.2 & 0
\end{tabular}

Again, the fuzzy transformation is performed according to the comprehensive evaluation vector formula S=W0V and normalized to obtain: $S^{\prime}=(0.356,0.292,0.160,0.120,0.092)$.

\begin{tabular}{|c|c|c|c|c|}
\hline \multirow{10}{*}{$\begin{array}{c}\text { Risk } \\
\text { assessment } \\
\text { indicator } \\
\text { weight }\end{array}$} & First level indicator & Weights & Second level indicator & Weights \\
\hline & \multirow{2}{*}{ Process design } & \multirow{2}{*}{$\mathrm{W} 1=0.433$} & $\begin{array}{c}\text { Standardization of operational process } \\
\text { design }\end{array}$ & $\mathrm{W} 11=0.685$ \\
\hline & & & Rationality of operational process design & $\mathrm{W} 12=0.315$ \\
\hline & \multirow{3}{*}{ Operational risk } & \multirow{3}{*}{$\mathrm{W} 2=0.252$} & Platform system stability & $\mathrm{W} 21=0.353$ \\
\hline & & & Platform system security & $\mathrm{W} 22=0.469$ \\
\hline & & & Platform system advancement & $\mathrm{W} 23=0.178$ \\
\hline & \multirow{2}{*}{ Technical operational risk } & \multirow[b]{2}{*}{$\mathrm{W} 3=0.072$} & Proficiency of personnel & $\mathrm{W} 31=0.532$ \\
\hline & & & Fraud risk & $\mathrm{W} 32=0.468$ \\
\hline & \multirow{2}{*}{ Personnel operation risk } & \multirow[b]{2}{*}{$\mathrm{W} 4=0.109$} & Pick up risk & $\mathrm{W} 41=0.667$ \\
\hline & & & Warehousing risk & $\mathrm{W} 42=0.333$ \\
\hline
\end{tabular}

According to the weighted average principle, the comprehensive evaluation is carried out, and S' is multiplied by the fuzzy evaluation vector $\mathrm{R}$ to obtain the operation risk evaluation result score of the Internet supply chain financial service project:

$\mathrm{u}=\mathrm{s}^{\prime} * \mathrm{RT}=(0.356,0.292,0.160,0.120,0.092) *(50,40,30,20,10) \mathrm{T}=37.6$ 
According to the evaluation level, $\mathrm{u}=37.6$, the operational risk belongs to a relatively small level.

\section{Conclusion}

Internet supply chain finance enhances service efficiency and financing ability of SMEs through online operation mode, but at the same time, due to many participants, many operational steps and links, the operational risks arising from the new links and the operational risks generated by traditional processes Superimposed on each other. This paper takes the Internet supply chain financial business model as the starting point, analyzes the operational risks that may occur in each link, and constructs an evaluation index system. The analytic hierarchy process is used to determine the weight of each indicator. By introducing the fuzzy comprehensive evaluation method to the Internet supply chain finance Operational risk is evaluated. The evaluation indicators and evaluation results can be used as the basis for the optimization operation of the participants in the Internet supply chain finance, and also provide reference for the evaluation of financial operation risks of other Internet supply chains.

\section{References}

[1] Tan Y, Liu M, Yang L I, et al. Research on Risk Assessment of Internet Public Opinion in Frontier Regions[J]. China Public Security, 2017.

[2] Fang Z, Chen J J, Xie T, et al. Research on Application of Cluster Analysis and AHP in Fire Risk Assessment of Shopping malls[J]. Mathematical Geosciences, 2015, 41(1):29-42.

[3] Tan, Y., Liu, M., Yang, L. I., \& Zhu, L. (2017). Research on risk assessment of internet public opinion in frontier regions. China Public Security.

[4] Liu H, Cao X, Finance S O, et al. Strategy Research of the Supply Chain Finance's Risk Assessment and Audit Management_—Based on the Research of Jiangsu Province[J]. Research of Finance \& Education, 2016.

[5] Zhan Q, Zhou J. Research on Spatial Distribution of Potential Fire Spots and Risk Assessment in Urban Areas - Case Study of Gulou District, Fuzhou, China[C]// International Conference on Management and Service Science. IEEE, 2011:1-4. 